slide performed by a researcher blinded to the groups. Data are expressed as median and IOR, and the groups were compared by the Kruskal-Wallis or Mann-Whitney U test.

Results (1) PAH specimens showed co-localisation of p65 within CD68+ macrophages in 75.4 (64.8-84.6)\% of samples. Airway epithelium, neutrophils and lymphocytes were also positive for p65. (2) Pulmonary arterial medial thickness was increased in PAH compared to controls, at 33.7 (18.8-67.9)\% in vessels $100-250 \mathrm{~mm}$ external diameter (E.D.) and $27.2(14.8-44.2) \%$ in vessels 250-500 $\mathrm{mm} \mathrm{ED,} \mathrm{vs} 17.7$ (11.2-30.3)\% and 14.9 (11.8-17.8)\% in controls ( $p<0.0001$ between groups). (3) Nuclear $p 65$ was present in pulmonary artery endothelial cells (EC) but not other vascular cells including pulmonary artery smooth muscle cells in PAH: 53.9 $(0-100) \%$ of vessels $100-250 \mathrm{~mm}$ E.D. and $53.1(0-100) \%$ of those 250-500 mm E.D. scored EC p65 positivity in PAH compared to 7.5 $(0-25.0) \%$ in $100-250 \mathrm{~mm}$ ED and $4.7(0-21.1) \%$ in $250-500 \mathrm{~mm}$ ED in controls ( $p<0.0001$ between groups) (Abstract P29 Figure 1).

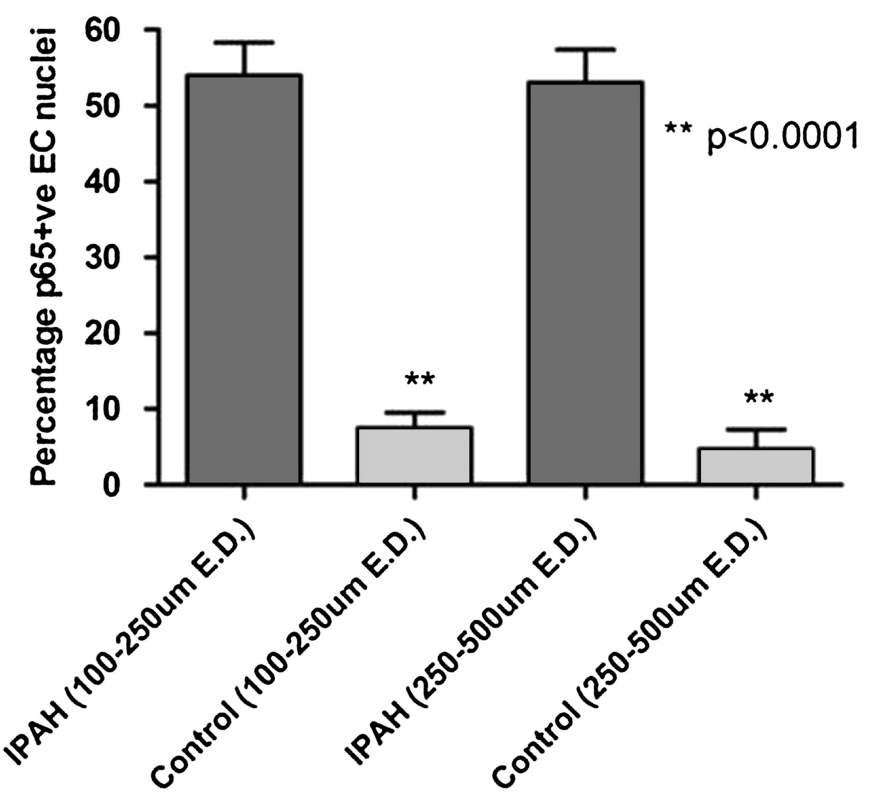

Abstract P29 Figure 1 Percentage of positive endothelial cell (EC) nuclear p65 immunostaining subdivided according to pulmonary artery external diameter (E.D.).

Conclusion NF-kB activation is present in macrophages and pulmonary arterial endothelial cells in pulmonary arteries of $100-500 \mathrm{~mm}$ ED in patients with PAH.

\section{P30 THE CHANGING FACE OF PULMONARY HYPERTENSION: THE ROLE OF HEART AND LUNG DISEASE}

doi:10.1136/thx.2010.150961.30

SF Crawley, MK Johnson, AJ Peacock. Scottish Pulmonary Vascular Unit (SPVU), Glasgow, UK

Introduction The advent of disease-targeted therapy for pulmonary arterial hypertension (PAH) has led to an increased awareness of this condition within the general cardiology and respiratory communities. More patients are being referred to specialist centres for diagnostic assessment, however there is concern that many will have pulmonary hypertension $(\mathrm{PH})$ due to underlying lung disease or left heart disease.

Aim The aim of the study was to review the outcome of diagnostic admissions to the Scottish Pulmonary Vascular Unit (SPVU) before
(2003-2005) and after (2006-2009) the introduction of diseasetargeted PAH therapy.

Methods 470 new patients with suspected $\mathrm{PH}$ were admitted between January 2003 and December 2009 for diagnostic assessment including right heart catheterisation (RHC). Demographic and haemodynamic data from these patients were retrospectively reviewed. Following RHC patients were diagnosed with:

- Group 1. PAH;

- Group 2. Pulmonary venous hypertension (PVH) due to left heart disease;

- Group 3. PH due to hypoxic lung disease (HLDPH);

- Group 4. Chronic thromboembolic PH (CTEPH);

- Group 5. PH due to unclear multifactorial mechanisms ( $\mathrm{PH}$ Misc);

\section{- No PH.}

Results In 2003-2005, 114 patients underwent diagnostic assessment, and 112 had $\mathrm{PH}$. Of these $77.7 \%$ had $\mathrm{PAH}$ and $18.8 \%$ had CTEPH. Only $2.7 \%$ of patients had PVH and $0.8 \%$ had HLDPH. In 2006-2009, 356 patients underwent diagnostic assessment, and 308 had $\mathrm{PH}$. Of these only $51.9 \%$ had PAH and $15.9 \%$ had CTEPH. However, now $17.9 \%$ of patients had PVH, and $10.4 \%$ had HLDPH 48 patients had No $\mathrm{PH}$ at the time of RHC (Abstract P30 Figure 1).

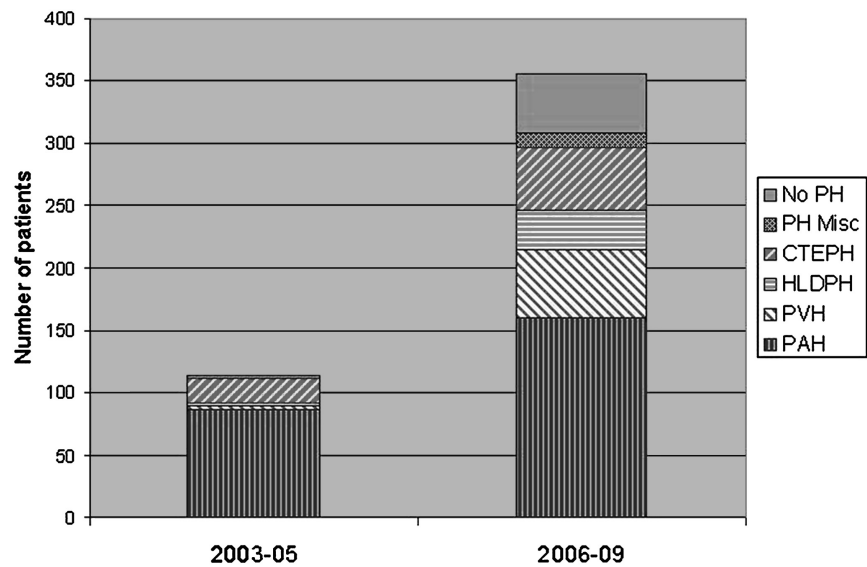

Abstract P30 Figure 1 Outcome of diagnostic assessment in the pre and post-treatment era.

Conclusion Prior to admission all referrals are screened by an SPVU consultant, but despite this there are a significant number of patients proceeding to RHC who will have $\mathrm{PH}$ due to left heart or lung disease. This highlights the importance of fully assessing all patients with suspected PH, as per ESC/ERS 2009 guidelines, before instituting expensive and potentially dangerous $\mathrm{PAH}$ therapy. We need to improve our non-invasive screening methods so that fewer patients proceed to RHC who do not have PAH.

\section{P31 DISEASE TARGETED THERAPIES AND EFFECT ON SURVIVAL IN IDIOPATHIC, HERITABLE AND ANOREXIGEN- ASSOCIATED PULMONARY ARTERIAL HYPERTENSION (PAH)}

doi:10.1136/thx.2010.150961.31

Y Ling, M Johnson, A Peacock. Scottish Pulmonary Vascular Unit, Glasgow, UK

Introduction The median survival of idiopathic PAH was 2.8 years before the availability of modern therapies. Substantial progress has been made over the past 20 years. Currently available disease targeted therapies have been shown in clinical trials to improve symptoms, exercise capacity and survival. Combination therapies 
should also be considered in patients with inadequate clinical response to monotherapy (ESC/ERS 2009). We aim to assess the use of modern advance treatments in 'real-life' patients and their impact on survival.

Methods A retrospective review of all incident cases of idiopathic, heritable and anorexigen-associated PAH diagnosed between 1st January 2001 and 31st December 2009 in our unit. Baseline and follow-up data were collected from case notes and local pulmonary hypertension database.

Results 94 incident cases were diagnosed ( $62 \%$ female) with median age of 63 years. $36 \%(n=34)$ of patients were on combination therapy. All except one patient were started on monotherapy, with second agent added at later stage. The median time from initiation of monotherapy to introduction of the second agent was 244 days. $25 \%$ had prostanoids; $51 \%$ endothelin receptor antagonists and $81 \%$ phosphodiesterase type- 5 inhibitor at some point of their treatment. The median survival is 5.63 years. We performed further analysis on the 28 patients who have died by censor date. Only seven patients were on prostanoids and eight patients on combination therapy. Possible explanations for low proportions of dead patients on prostanoids and/or combination therapy are outlined in Abstract P31 Table 1.

Abstract P31 Table 1 Possible explanations why prostanoids or combination therapies were not started

\begin{tabular}{ll}
\hline & Number of dead patients (total=28) \\
\hline Already on prostanoids & 7 \\
$\begin{array}{l}\text { Died from unrelated causes } \\
\text { Prostanoids considered but felt inappropriate, } \\
\text { for palliation only }\end{array}$ & 6 \\
$\begin{array}{l}\text { No documented explanation } \\
\begin{array}{l}\text { Treatment optimised less than } 4 \text { months } \\
\text { before death }\end{array}\end{array}$ & 3 \\
$\begin{array}{l}\text { Clinically improving at last clinic review } \\
\text { before death }\end{array}$ & 2 \\
$\begin{array}{l}\text { Sudden unexpected death } \\
\text { Lost to follow up }\end{array}$ & 1 \\
Poor compliance, frequent non-attendance of \\
clinics
\end{tabular}

Conclusion Our results demonstrate improved survival compared to pre-advance therapy era. Apart from proven efficacy of various $\mathrm{PAH}$ specific treatment, several other factors may also influence the treatment decision for individual patient.

\section{P32 DELIVERING PULMONARY HYPERTENSION SERVICES-5 YEAR EXPERIENCE FROM A SATELLITE CENTRE}

doi:10.1136/thx.2010.150961.32

${ }^{1} \mathrm{~S}$ Sturney, ${ }^{2} \mathrm{~S}$ Reddecliffe, ${ }^{1} \mathrm{H}$ Davies, ${ }^{1} \mathrm{G}$ Robinson, ${ }^{1} \mathrm{~J}$ Easaw, ${ }^{1} \mathrm{~J}$ Suntharalingam, ${ }^{2} \mathrm{G}$ Coghlan. ${ }^{1}$ Royal United Hospital, Bath, UK; ${ }^{2}$ Royal Free Hospital, London, UK

Introduction There are currently no National Commissioning Group (NCG) designated Pulmonary Hypertension ( $\mathrm{PH}$ ) centres in the South West. As a result patients can travel up to 300 miles to access specialist care. In 2005, a satellite service was developed at the Royal United Hospital (RUH), Bath in conjunction with the Royal Free, London. Initially the service simply provided a follow up service for patients known to the Royal Free. Since 2007 the service has fully investigated and managed new referrals locally, with supervision from the Royal Free. Patients have typically only needed to travel to an NCG centre for initiation of parenteral prostanoid therapy or for pulmonary endarterectomy (PEA).
Aim This abstract describes the first 5 years of activity by the RUH satellite PH service.

Results As of 1st July 2010, 147 new referrals have been received, increasing steadily from 7/year in 2005-2006 to 57/year in 2009-2010. Referrals originated from 7 specialities across 12 PCTs, with $48.6 \%$ from outside the immediate catchment area. 43 patients were diagnosed with Pulmonary Arterial Hypertension (PAH) (including 34 with Connective Tissue Disease-related PAH), 21 with Chronic Thromboembolic Pulmonary Hypertension (CTEPH) (including 15 referred for PEA surgery), 13 with $\mathrm{PH}$ associated with lung disease, 24 with $\mathrm{PH}$ associated with left heart disease. $\mathrm{PH}$ was excluded in 45 cases. 62 have received $\mathrm{PH}$-specific medication; 38 monotherapy and 24 combination therapy (including 7 intravenous, 1 subcutaneous and 2 nebulised prostanoid therapy). Survival data for the 38 treated WHO Group 1 PAH patients compares favourably with published data for NCG designated centres; $89.5 \%$ at 1 year (95\% CI $74.2 \%$ to $96.6 \%$ ), $82.3 \%$ at 2 years (95\% CI $65.9 \%$ to $92.2 \%$ ) and $77.2 \%$ at 3 years ( $95 \%$ CI $60.3 \%$ to $88.6 \%$ ). 489 journeys were made to the RUH and only 60 to NCG centres, saving approximately 56000 patient miles. A recent patient survey indicated high levels of satisfaction, with $94.4 \%$ stating they would rather continue follow-up locally.

Discussion These results suggest that a comprehensive $\mathrm{PH}$ specialist service can be delivered locally in a way that is more convenient for patients whilst still maintaining national standards of care.

\section{P33 \\ IRON DEFICIENCY INDEPENDENTLY PREDICTS SURVIVAL IN IDIOPATHIC PULMONARY ARTERIAL HYPERTENSION}

doi:10.1136/thx.2010.150961.33

CJ Rhodes, LS Howard, M Busbridge, D Ashby, E Kondili, JSR Gibbs, J Wharton, MR Wilkins. Imperial College London, London, UK

Objectives Characterise the iron status of patients with idiopathic pulmonary arterial hypertension (IPAH) and its clinical importance.

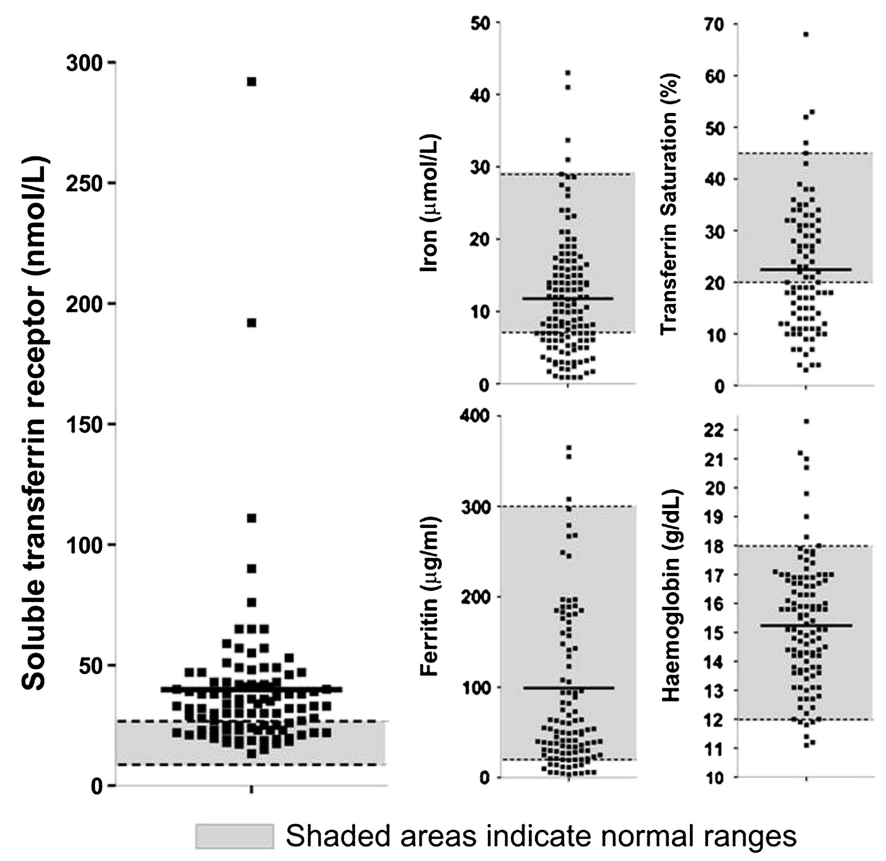

Abstract P33 Figure 1 